\title{
Evaluation of fracture toughness and Charpy V-notch test correlations for selected Al alloys
}

\author{
Rasid Ahmed Yildiz ${ }^{1,2^{*}}$ \\ 'TUBITAK, Informatics, and Information Security Research Center, Gebze-Kocaeli, 4I470, Turkey, ${ }^{2}$ Department of Mechanical Engineering, Istanbul \\ Technical University, Beyoglu, 34437 Istanbul, Turkey
}

Orcid: R.A. Yildiz (0000-0003-2066-3।38)

\begin{abstract}
This research experimentally compared the correlations between fracture toughness and Charpy V-notch tests. The fracture toughness tests are expensive, complex, and laborious. Therefore, researchers developed correlations to estimate fracture toughness using Charpy $\vee$-notch tests, thereby structural integrity assessment. For the current work, nine different fracture toughness correlations were selected using the existing literature, and most common Al alloys, including 2024-T4, 606I-T6, and 7075-T6, were chosen as testing materials. Tensile tests were utilized to determine the deformation behavior of the tested alloys. Also, Charpy V-notch tests were carried out to obtain absorbed energy during the low impact conditions. Rupture strain, yield, and ultimate tensile strengths of the alloys were determined by tensile testing. Charpy $V$-notch test results revealed that the energy absorption ability of the 606I-T6 Al alloy is roughly two times higher than the 2024-T4 and roughly four times higher than the 7075T6 Al alloy. The fracture toughness estimations resulted in a broad range of values. The experimentally obtained fracture toughness values attained from the literature were used to define the error of each correlation. One of the tested correlation yielded the lowest average error with an error percentage of $15.6 \%$. Lastly, the ductile fracture of the $606 \mathrm{I}-\mathrm{T} 6 \mathrm{Al}$ alloy tensile test specimens executed at the quasi-static conditions was attributed to having a higher fracture toughness.
\end{abstract}

Keywords: Fracture toughness, Charpy V-notch test, Deformation behavior, 2024-T4 Al alloy, 606I-T6 Al alloy, 7075-T6 Al alloy.

\section{Introduction}

Design engineers decide the material considering its mechanical behavior: yield strength, tensile strength, fatigue properties, creep properties, hardness, impact behavior, and fracture toughness $\left(\mathrm{K}_{\mathrm{c}}\right)$. According to the linear elastic fracture mechanics (LEFM), fracture toughness is defined as the magnitude of stress intensity at the tip of a crack where the strain in the body is elastic. In other words, fracture toughness could be described as the fracture resistance of a material with an intrinsic crack [1]. If the crack tip zone of the materials is taken into consideration, the stress field at the ductile metals is plastic, microcracking in ceramics, and delamination and debonding in composites [2]. ASTM E-399 standard [3] is commonly used to determine the fracture toughness of the materials in planar strain. However, the execution of the standard fracture toughness experiments returns a high cost in addition to the complexity. Therefore, researchers searched for other methodologies to determine the fracture toughness of the materials, e.g., using Charpy V-notch tests [4-7].

Scholars studied the fracture toughness correlations for welded joints to determine structural integrity, a possi- ble failure locus in the structures. They estimated the fracture toughness of steel joints using Charpy impact tests [8-10]. Similarly, Zhou and colleagues used Charpy impact specimens to obtain fracture toughness and thus minimum design metal temperature of irradiated steels preferred in the nuclear industry [11].

Moreover, Puppala et al. evaluated the fracture toughness and Charpy V-notch tests of Inconel 625 parts fabricated by metal additive manufacturing. They calculated the dynamic yield strength by using a general yield load. Next, they estimated the initiation fracture toughness in terms of absorbed energy. Also, they asserted that the crack tip opening displacement fracture toughness values are similar to the welded Inconel 625 [12].

On the other hand, the studies on fracture toughness and Charpy V-notch test correlations are limited for $\mathrm{Al}$ alloys. Therefore, Hemmouche and co-workers [13] investigated the effect of heat treatments on the fracture toughness of the 2017A Al alloy. They carried out both the three-point bending and Charpy impact tests to investigate the fracture toughness and crack propagation of the alloy for T4, T6, and T7 temper conditions. According to their study, the fracture toughness was dependent on the hardness 


\begin{tabular}{|c|c|c|c|c|}
\hline Ref. & Authors & Temperature & Material & Equation \\
\hline [20] & Rolfe-Novak-Barson & Upper-shelf & High strength steels & $K_{c}=\sigma_{Y} \sqrt{0.64}\left(\frac{C I E}{\sigma_{Y}}-0.01\right)$ \\
\hline$[2 ।]$ & Kleinberg et al. & Upper-shelf & SA-533B steel & $K_{c}=20+139\left(\frac{196}{C I E}-1\right)^{-0.54}$ \\
\hline [22] & Rao and Achary & Upper-shelf & M250 maraging steel & $K_{C}=\sigma_{Y} \sqrt{0.54\left(\frac{C I E}{\sigma_{Y}}-0.02\right)}$ \\
\hline [23] & Sailors and Corten & Transition-range & High strength steels & $K_{c}=14.6 \sqrt{C I E}$ \\
\hline [24] & Marandet and Sanz & Transition-range & A533B medium strength steels & $K_{c}=19 \sqrt{C I E}$ \\
\hline [25] & Roberts and Newton & Upper-shelf & Bridge steels & $K_{c}=\sigma_{Y} \sqrt{\left(\frac{13.0858}{\left(\frac{\sigma_{Y}}{C I E}\right)^{3}}\right)}$ \\
\hline [26] & Kussmaul and Ross & Upper-shelf & $20 \mathrm{MnMoNi5}$ steel & $K_{c}=\sigma_{Y} \sqrt{1.23\left(\frac{C I E}{\sigma_{Y}}-0.0061\right)}$ \\
\hline [27] & Lucan et al. & Upper-shelf & Ferritic structural steels & $K_{c}=\sqrt{\frac{E\left(0.53 C I E^{1.28}\right)\left(0.2^{\left.0.133 C I E^{0.256}\right)}\right.}{1000\left(1-v^{2}\right)}}$ \\
\hline [28] & Li et al. & Upper-shelf & SA508-III steel & $K_{c}=\sigma_{Y} \sqrt{0.3316\left(\frac{C I E}{\sigma_{Y}}+0.7\right)}$ \\
\hline
\end{tabular}

of the material. The highest fracture toughness value was obtained when the peak-strength condition is reached.

Aluminum and its alloys have been used widely, especially in the aerospace/aircraft and automotive industries [14-16]. During the design phase of a part, engineers demand high strength considering safety factors and design requirements. Nonetheless, manufacturing engineers prefer high ductility regarding the material's deformation behavior [17]. Within this context, age-hardened or, in other words, precipitation-hardened $\mathrm{Al}$ alloys are favorable for both design and manufacturing engineers. Therefore, the three most common precipitation hardenable $\mathrm{Al}$ alloys in the industry were subjected to the study: 2024-T4, 6061T6, and 7075-T6. 2024 and $7075 \mathrm{Al}$ alloys are generally preferred by the aerospace and aircraft industry [18]. On the other hand, $6061 \mathrm{Al}$ alloy is favorable for many engineering applications, including aircraft, automotive, high-speed train, and marine applications as advanced structural components [19].

The aforementioned studies on the Charpy V-notch tests and fracture toughness correlations were primarily investigated steels and welded materials. In fact, $\mathrm{Al}$ alloys constitute a wide range of usage areas as a material in the automotive, aerospace, and aircraft industries. The paper compares the correlations between Charpy impact energies and fracture toughness and defines the most appropriate empirical correlations -proposed by different researchers- for the most common $\mathrm{Al}$ alloys. The calculation methodology, depending on the material properties, including Young modulus, Poisson's ratio, impact energy and yield strength, affects the results. This study presents and compares with the fracture toughness values with the existing literature.

In the present work, the theoretical methods to calculate fracture toughness of the alloys using Charpy impact energy values are given in Section 2. In Section 3, materials and the experimental methodologies, including tensile testing and Charpy V-notch tests, are described. In Section 4, the results of the tensile testing and Charpy $\mathrm{V}$-notch tests are shown. Further, fracture toughness estimations using the proposed equations are represented. In Section 5, the experimental results were discussed using the fracture toughness values in the literature. Lastly, the concluding remarks were exhibited in Section 6.

\section{Theoretical Methods}

There have been numerous studies in the literature to calculate fracture toughness by using practical Charpy $\mathrm{V}$-notch tests. The correlations evaluated in the current work between the fracture toughness $\left(K_{c}\right)$ and Charpy impact energy $(C I E)$ of the materials are given in Table 1. The yield strength of the material is defined as $\sigma_{\varphi}$, Young modulus as $E$, and Poisson's ratio as $v$ in the Table 1 . As commonly known, there is a ductile-brittle transition 
temperature for the body-centric cubic material structures. The alloys show ductile fracture at temperatures higher than the transition range, while they represent a brittle fracture at the lower temperature values. However, $\mathrm{Al}$ alloys do not demonstrate any ductile-brittle transition temperature as apparent for most steels.

\section{EXPERIMENTAL METHODS}

\section{I. Material}

In the current work, commercially available 2024-T4, 6061-T6, and 7075-T6 Al alloys were used to compare the fracture toughness correlations with the experimentally obtained Charpy V-notch test results. The alloys' chemical compositions and temper conditions were received from the distributor with inspection certificates (Table 2).

\subsection{Tensile Testing}

Researchers incorporate yield stress into the correlations between Charpy V-notch tests and fracture toughness, as given in Table 1. Therefore, the yield stress values of the selected $\mathrm{Al}$ alloys were obtained through tensile tests. The tensile tests were accomplished in accordance with ASTM E8-09: Standard test methods for tension testing of metallic materials [29]. The testing machine used in the tensile tests was Shimadzu Autograph $(50 \mathrm{kN})$ with a video extensometer. Two CCD cameras recorded the elongation during the tests. The velocity of the ram was selected as $3 \mathrm{~mm} / \mathrm{min}$, which corresponds to an initial strain rate of $7.14 \times 10^{-4} \mathrm{~s}^{-1}$. Three individual waisted test specimens were machined from the stock having a diameter of $9 \mathrm{~mm}$ and a gauge length of $45 \mathrm{~mm}$. The dimensions of the tensile specimens are exhibited in Figure 1.

\subsection{Charpy V-Notch Tests}

Charpy V-notch tests were very practical experiments to determine the relative energy absorption capability of the materials. Within the study, Charpy V-notch tests were carried out to determine the fracture toughness of the se-

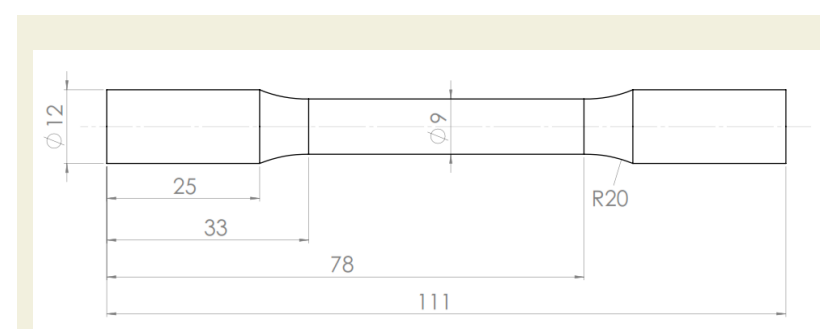

Figure 1. Dimensions of the tensile testing specimen regarding to ASTM E8-09 [29]. lected $\mathrm{Al}$ alloys. The experiments were conducted only at room temperature. Three individual V-notched test specimens having a length of $55 \mathrm{~mm}, 8 \mathrm{~mm}$ ligament length, and $45^{\circ}$ angles of the notch were prepared, as shown in Figure 2. The V-notched specimens were machined from the stock.

\section{EXPERIMENTAL RESULTS AND DISCUSSION}

\section{I. Tensile Testing Results}

According to the correlations given in Table 1, the fracture toughness calculations require yield stress data. Therefore, the correlations were mainly constructed on the yield stress of the material and empirical coefficients. To determine the yield stress of the 2024-T6 Al alloy, tensile tests were carried out. Before the execution of the tests, the waisted diameter of the specimens was noted down. These values were then used to calculate the yield and ultimate tensile strength of the metal. Figure 3 represents the load-displacement curve of the tested material. Three different test specimens were consumed for the experiments.

According to Figure 3, for the same gauge diameter, the highest tensile strength was observed at 7075-T6 among

the tested alloys. Nonetheless, 2024-T4 Al alloy demonstrated the lowest tensile strength. Besides, the brittle nature of the 2024-T4 and 7075-T6 is evident due to the limited elongation after strain localization. After the initiation of necking, the materials demonstrate a modest plastic deformation until rupture. On the other hand, 6061-T6 Al alloy has the highest ductility among tested alloys. The decrease in the force after necking continued for a significant displacement until rupture, as seen in Figure 3. Also, the fractured tensile test specimens can be seen in Figure 4. The reduction in the necked regions of 2024-T4 and 7075-T6 is scarce and agrees well with the load-displacement curves. Nevertheless, the reduction in

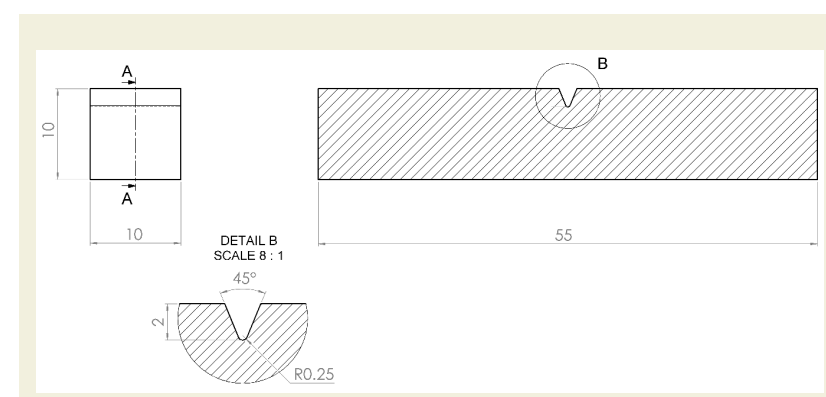

Figure 2. Dimensions of the V-notched Charpy impact test specimen regarding ASTM E23-18 [30].

Table 2. Chemical Compositions of the Al Alloys.

\begin{tabular}{|c|c|c|c|c|c|c|c|c|c|c|}
\hline Alloy & Al & $\mathrm{Mg}$ & $\mathrm{Si}$ & $\mathrm{Fe}$ & $\mathrm{Cu}$ & Zn & $\mathrm{Ti}$ & Mn & $\mathrm{Cr}$ & $\mathbf{Z r}$ \\
\hline 2024 & Balance & 1.27 & 0.27 & 0.39 & 3.96 & 0.12 & 0.02 & 0.50 & 0.02 & 0.01 \\
\hline 6061 & Balance & 0.82 & 0.64 & 0.17 & 0.23 & 0.01 & 0.02 & 0.15 & 0.08 & - \\
\hline 7075 & Balance & 2.46 & 0.15 & 0.25 & 1.51 & 5.62 & 0.04 & 0.15 & 0.19 & - \\
\hline
\end{tabular}




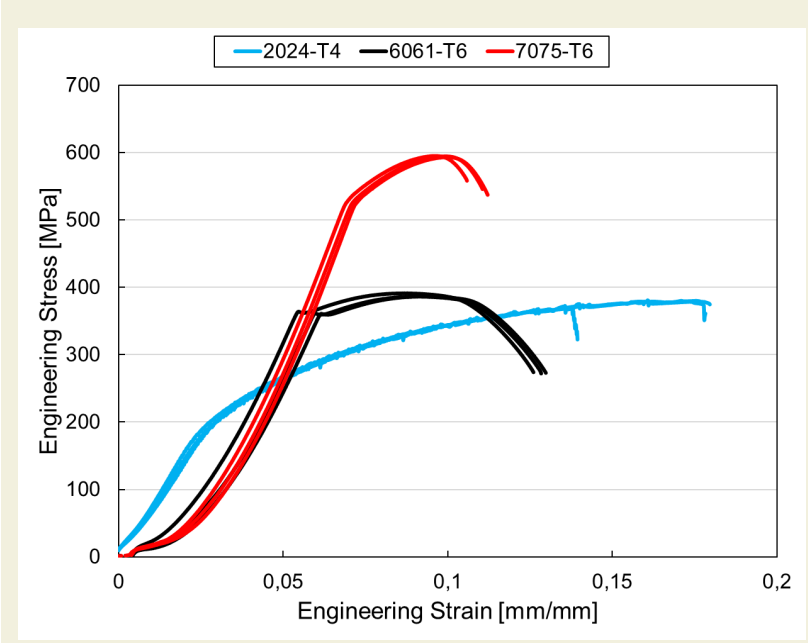

Figure 3. Engineering Stress-Strain Curves for 2024-T4, 6061-T6 and 7075-T6 Al Alloy.
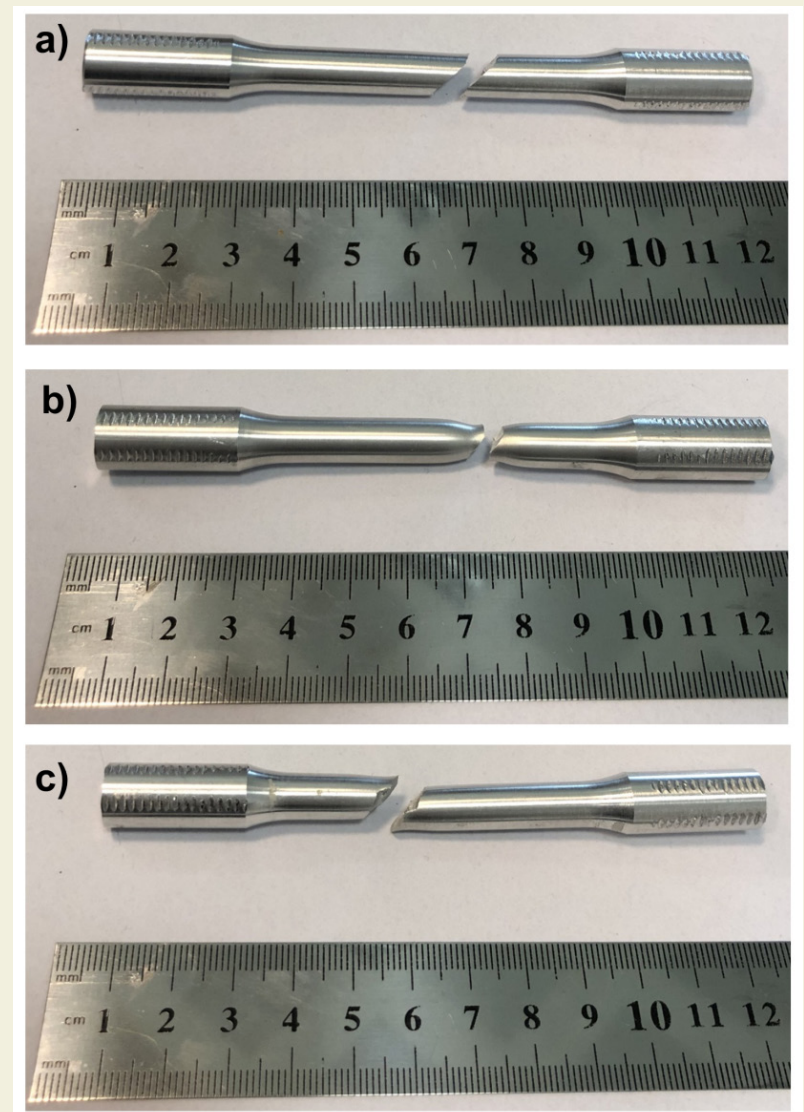

Figure 4. Fractured Tensile Test Specimens a) 2024-T4 b) 6061-T6 c) 7075-T6 Al alloy.

the 6061-T6, as shown in Figure 4b, is apparent. This reduction was also expected due to the ductile characteristic of the alloy that consistent with the deformation behavior of the alloy.

The average ultimate tensile strength (UTS) and average yield strength (YS) of tested specimens were represented in Table 3. A statistical approach was used for a 95\% confidence level:

$x=\bar{x} \pm z^{*} \frac{s}{\sqrt{n}}$
In Equation 1, $x$ is the range of samples for a given confidence interval, $\bar{x}$ is the average value of the samples, $z^{*}$ is the confidence level that is 1.96 for $95 \%, s$ is the standard deviation of the samples, and $n$ is the number of the samples. Table 3 shows the tensile properties of the tested Al alloys.

Stress-strain properties of the tested Al alloys demonstrated yield and ultimate tensile strength in accordance with the literature values [31]. Design engineers prefer 2024T4, 6061-T6, and 7075-T6 Al alloys as structural materials in the aerospace industry, having high strength with a relatively low density. Thus, the tensile testing results were not surprising in terms of mechanical behavior.

\subsection{Charpy V-Notch Test Results}

Charpy impact tests were carried out to compare the fracture toughness correlations presented in the literature. Charpy V-notch tests generate a low impact on the specimens, and the brittle characteristics of the alloys yielded to a brittle fracture, as shown in Figure 5. The specimens were separated into two pieces during the tests. The specimens evinced very flat fracture surfaces, which is consistent with the impact energy observed.

As commonly known, the outcomes of impact tests are generally used to compare the metals' energy absorption abilities relatively. Thus, the energy absorption capability of the alloy was tested by using a practical approach within the study. According to the test results, the Charpy impact energies of the tested alloys were tabulated in Table 4. At least three different specimens were consumed for each alloy, and the average values with a $95 \%$ confidence level are given in Table 4.

\subsection{Calculation of the Fracture Toughness Correlations}

The fracture toughness calculations were executed in accordance with the equations given in Table 1 . The calculated values for fracture toughness results are given in $\mathrm{Ta}$ ble 3. According to the calculations, a broad range for the fracture toughness values was observed. The lowest calculation results were obtained when the equation developed by Roberts and Newton was utilized. On the other hand, the method proposed by Li et al. resulted in the highest values.

Estimated values for the fracture toughness calculations by using Charpy impact energies were also displayed in Figure 6 . The fracture toughness values calculated by different approaches show that the 2024-T4 and 7075-T6 Al alloys have similar values. On the other hand, 6061-T6 Al alloy represents higher values except for the calculation methodology of Li et al. Among the tested calculation approaches, the results for the equation proposed by Li et al. are much higher than the average. 


\begin{tabular}{|c|c|c|c|c|c|c|c|}
\hline Al Alloy & $\begin{array}{c}\text { Specimen } \\
\text { No }\end{array}$ & YS [MPa] & UTS [MPa] & $\begin{array}{c}\text { Rupture Strain } \\
{[\%]}\end{array}$ & $\begin{array}{l}\text { Average Rupture } \\
\text { Strain [\%] }\end{array}$ & $\begin{array}{l}\text { Average } \\
\text { YS [MPa] }\end{array}$ & $\begin{array}{l}\text { Average } \\
\text { UTS [MPa] }\end{array}$ \\
\hline \multirow{3}{*}{ 2024-T4 } & $1-1$ & 241.6 & 372.5 & 10.4 & \multirow{3}{*}{$12.4 \pm 1.5$} & \multirow{3}{*}{$248.4 \pm 12.7$} & \multirow{3}{*}{$372.8 \pm 1.4$} \\
\hline & $1-2$ & 237.4 & 374.6 & 13.5 & & & \\
\hline & $1-3$ & 266.2 & 371.3 & 13.1 & & & \\
\hline \multirow{3}{*}{ 606I-T6 } & $4-1$ & 307.8 & 381.9 & 7.5 & \multirow{3}{*}{$7.4 \pm 0.1$} & \multirow{3}{*}{$316.9 \pm 6.5$} & \multirow{3}{*}{$373.6 \pm 6.3$} \\
\hline & $4-2$ & 320.4 & 372.1 & 7.3 & & & \\
\hline & $4-3$ & 322.6 & 366.8 & 7.5 & & & \\
\hline \multirow{3}{*}{ 7075-T6 } & $6-1$ & 455.8 & 595.2 & 4.1 & \multirow{3}{*}{$4.4 \pm 0.3$} & \multirow{3}{*}{$456.0 \pm 4.2$} & \multirow{3}{*}{$594.4 \pm 1.7$} \\
\hline & $6-2$ & 461.3 & 594.6 & 4.3 & & & \\
\hline & $6-3$ & 450.9 & 593.4 & 4.7 & & & \\
\hline
\end{tabular}
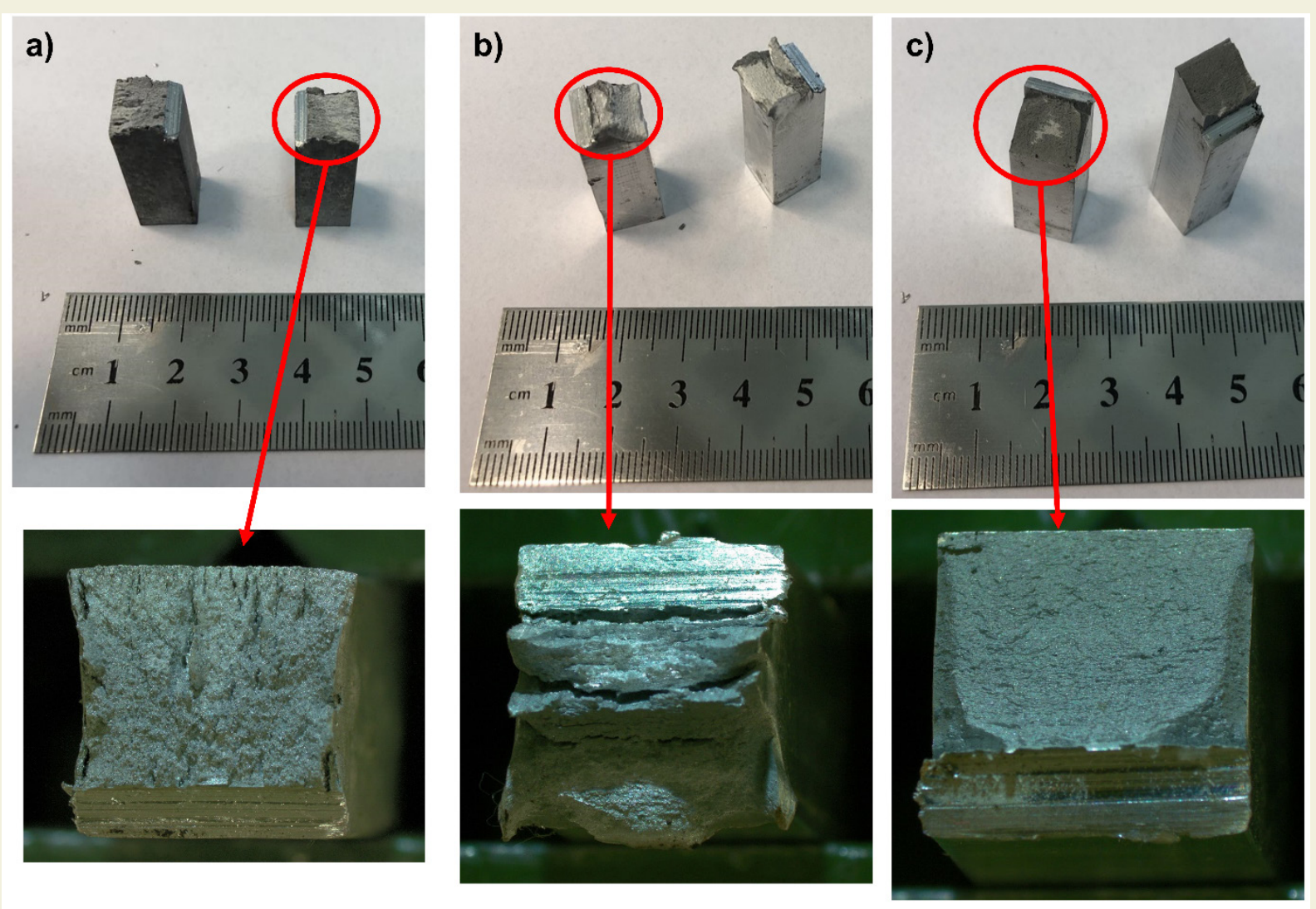

Figure 5. Fractured Charpy V-Notch Test Specimens a) 2024-T4 b) 6061-T6 c) 7075-T6 Al alloy.

Table 4. Charpy Impact Energy of the Tested Alloys

2024-T4 606I-T6 7075-T6

Charpy Impact Energy [J] $\quad 26.5 \pm 0.9 \quad 50.3 \pm 6.413 .1 \pm 1.0$

As it is commonly known, the fracture phenomenon creates two new surfaces associated with surface energy. The increase in fracture toughness could be attributed to the resistance to crack propagation. Figure 6 displays that the 6061-T6 Al alloy is more resistant to crack propagation having a high fracture toughness. Nevertheless, 2024$\mathrm{T} 4$ and 7075-T6 Al alloys demonstrated similar fracture toughness values, although they have different stressstrain properties.
Table 5. Fracture Toughness Estimations Conducted by Different Equations

\begin{tabular}{|c|c|c|c|c|}
\hline \multirow{2}{*}{ Reference } & \multirow{2}{*}{ Authors } & \multicolumn{3}{|c|}{ Fracture Toughness $[\mathrm{MPa} \sqrt{\mathrm{m}}]$} \\
\hline & & 2024-T4 & $6061-T 6$ & 7075-T6 \\
\hline [20] & Rolfe-Novak-Barson & 59.14 & 97.77 & 49.92 \\
\hline$[21]$ & Kleinberg et al. & 59.80 & 98.27 & 53.48 \\
\hline [22] & Rao and Achary & 45.56 & 86.74 & 31.31 \\
\hline [23] & Sailors and Corten & 61.25 & 103.55 & 52.84 \\
\hline [24] & Marandet and Sanz & 79.71 & 134.75 & 68.77 \\
\hline [25] & Roberts and Newton & 13.31 & 72.49 & 8.03 \\
\hline [26] & Kussmaul and Ross & 86.60 & |37.31 & 76.07 \\
\hline [27] & Lucan et al. & 32.16 & 58.79 & 27.06 \\
\hline [28] & Li et al. & 199.93 & 169.11 & 224.16 \\
\hline
\end{tabular}




\section{Discussion}

In the literature, researchers experimentally determine the fracture toughness of the selected alloys. These values were used to compare the calculations. Xing et al. determined the fracture toughness of 2024-T4 Al alloy as $35 \mathrm{MPa} \sqrt{\mathrm{m}}$ [32]. Also, MacMaster and colleagues obtained the fracture toughness of 6061-T6 Al alloy as 48.7 $\mathrm{MPa} \sqrt{\mathrm{m}}$ [33]. Lastly, Wang et al. revealed that the 7075$\mathrm{T} 6 \mathrm{Al}$ alloy has a fracture toughness of $33 \mathrm{MPa} \sqrt{\mathrm{m}}$ [34]. The experimental findings in the literature were utilized as reference values, and Figure 7 was generated. In Figure 7 , the error of each alloy is represented with different colors, i.e., blue for 2024-T4, black for 6061-T6, and red for 7075-T6 Al alloy. The sum of the total error percentage is demonstrated as a primary axis title. Besides, the average error for each equation was calculated as an average of errors for a specific equation, e.g., the average error value for 2024-T4 Al alloy was calculated, dividing the total error percentage by three.

According to Figure 7, it is clear that the lowest total error percentage and average error value were obtained when the equation proposed by Lucan et al. was employed. The average error for Lucan et al. was determined as $15.6 \%$. The main difference of Lucan et al. is their calculation methodology depends on the Young modulus and Poisson's ratio as an alternative to yield strength.

Then, the methodology proposed by Rao and Achary resulted in a $37.8 \%$ average error percentage. Also, their methodology estimated the fracture toughness of 7075$\mathrm{T} 6 \mathrm{Al}$ alloy with an error of less than 5\%. Their correlation was based on the $\frac{C I E}{\sigma_{Y}}$ ratio rather than the Young modulus and Poisson's ratio.

The equations proposed by Li et al. yielded an incredibly high error. This high percentage of error could be attributed to the correlation coefficients. Also, correlation of Charpy impact energy and fracture toughness, not including the yield strength, Young modulus, and Poisson's ratio, resulted in higher error according to the existing values in the literature.

During the deformation of the engineering alloys, strain localization occurs, follows by a loss in the load-carrying capacity in the alloy. Figure 3 and Figure 4 represent that the necking, or in other words, strain localization in the 6061-T6 was significant when compared to 2024-T4 and 7075-T6 Al alloys. This could be explained by the higher fracture toughness values of the 6061-T6 Al alloy. More energy was needed to release to form new surfaces in 6061-T6 Al alloy during the nucleation of new voids and the growth of the intrinsic voids.

\section{Conclusion}

Within the study, nine different correlations to estimate fracture toughness of the 2024-T4, 6061-T6, and 7075-T6 $\mathrm{Al}$ alloys using Charpy impact tests were compared, and

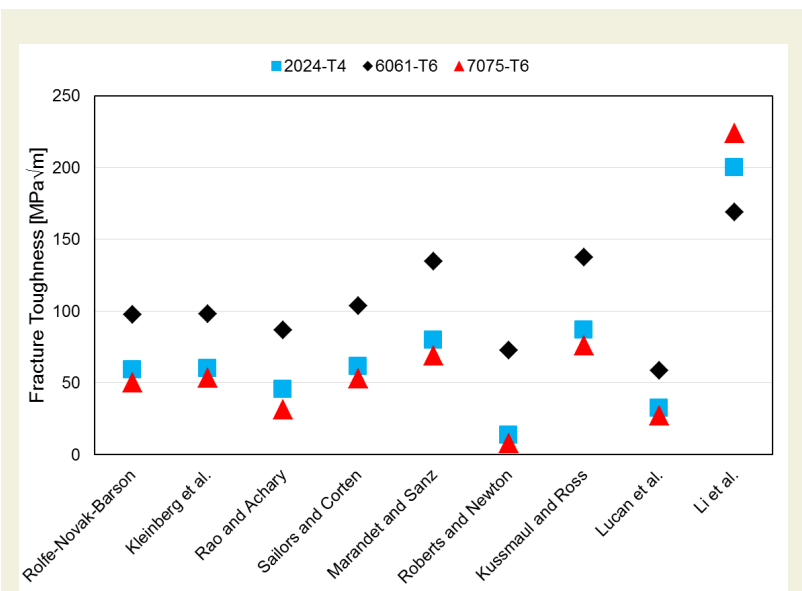

Figure 6. Fracture toughness values for different approaches.

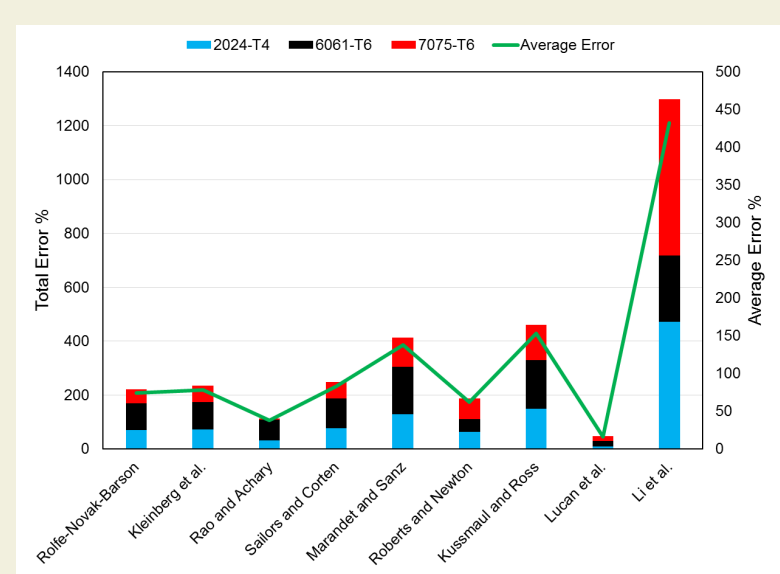

Figure 7. Total error for fracture toughness calculations considering different equations.

*The total and average error percentages indicate absolute values.

the following conclusions were drawn:

- The reduction in the necked region of the 6061-T6 Al alloy was apparent as an indicator of the ductile nature of the alloy.

- Charpy V-notch tests revealed that all of the tested alloys were divided into two parts with a bright surface, thereby representing a brittle fracture under low impact conditions.

- 6061-T6 Al alloy has the highest Charpy impact energy and also the highest fracture toughness values among the tested $\mathrm{Al}$ alloys.

- The correlation proposed by Lucan et al. provided the least error when the calculations were compared with the experimental fracture toughness values.

- The correlation dependent on the Young modulus and Poisson's ratio resulted in a minor error when compared to the equations based on the 'CIE, and
only 'CIE'.

\section{Rererences}

[1] Smith, R.J., Horn, A.J., Sherry, A.H., (2018). Relating Charpy energy to fracture toughness in the lower transition region 
using a Weibull stress dependent energy scaling model. International Journal of Pressure Vessels and Piping. 166: 72-83. doi: 10.1016/j.ijpvp.2018.06.001.

[2] Anderson, T.L., (2005). Fracture Mechanics. Boca Raton: CRC Press Taylor \& Francis Group.

[3] (2020). Standard Test Method for Linear-Elastic PlaneStrain Fracture Toughness of Metallic Materials. West Conshohocken, PA.

[4] Ritchie, R.O., Knott, J.F., Rice, J.R., (1973). On the relationship between critical tensile stress and fracture toughness in mild steel. Journal of the Mechanics and Physics of Solids. 21(6): 395-410. doi: 10.1016/0022-5096(73)90008-2.

[5] Rossoll, A., Berdin, C., Prioul, C., (2002). Determination of the fracture toughness of a low alloy steel by the instrumented charpy impact test. International Journal of Fracture. 115(3): 205-26. doi: 10.1023/A:1016323522441.

[6] Schindler, H.J., Morf, U., (1993). A closer look at estimation of fracture toughness from Charpy $\mathrm{V}$-notch tests. International Journal of Pressure Vessels and Piping. 55(2): 203-12. doi: 10.1016/0308-0161(93)90028-R.

[7] A Salemi Golezani., (2013). The Effect of Microstructure on Estimation of the Fracture Toughness (KIC) Rotor Steel Using Charpy Absorbed Energy (CVN). Journal of Advanced Materials and Processing. 1(3): 11-7.

[8] Terán, G., Capula-Colindres, S., Angeles-Herrera, D., Velázquez, J.C., Fernández-Cueto, M.J., (2016). Estimation of fracture toughness KIC from Charpy impact test data in T-welded connections repaired by grinding and wet welding. Engineering Fracture Mechanics. 153(January 2018): 351-9. doi: 10.1016/j.engfracmech.2015.12.010.

[9] Takashima, Y., Ito, Y., Lu, F., Minami, F., (2019). Fracture toughness evaluation for dissimilar steel joints by Charpy impact test. Welding in the World. 63(5): 1243-54. doi: 10.1007/s40194-019-00752-x.

[10] Bianchi, K.E., Barbosa, V.S., Savioli, R., Fernandes, P.E.A., Ruggieri, C., (2017). Correlation of Fracture Toughness With Charpy Impact Energy for Low Alloy, Structural Steel Welds. Volume 6B: Materials and Fabrication, American Society of Mechanical Engineers p. 1-11.

[11] Zhou, Z., Huang, S., Hui, H., Zhang, Y., (2020). Estimation of Minimum Design Metal Temperature by MDMT Curve and Correlations of Charpy Impact and Fracture Toughness. Journal of Pressure Vessel Technology. 142(6). doi: 10.1115/1.4046888.

[12] Puppala, G., Moitra, A., Sathyanarayanan, S., Kaul, R., Sasikala, G., Prasad, R.C., et al., (2014). Evaluation of fracture toughness and impact toughness of laser rapid manufactured Inconel-625 structures and their co-relation. Materials and Design. 59: 509-15. doi: 10.1016/j.matdes.2014.03.013.

[13] Hemmouche, L., Meghalet, A., Henni Chebra, A., (2018). Influence of Heat Treatments on the Fracture Toughness of 2017A Aluminium Alloy. Physics of Metals and Metallography. 119(3): 301-8. doi: 10.1134/S0031918X18010118.

[14] Uğurlu, M., Çakan, A., (2019). The Effect of Tool Rotation Speed on Mechanical Properties of Friction Stir Spot Welded (FSSW) AA7075-T6 Aluminium Alloy Sheets. European Mechanical Science. 3(3): 97-101. doi: 10.26701/ ems.520139.
[15] Şener, B., Akşen, T.A., Fırat, M., (2021). On the Effect of Through-Thickness Integration for the Blank Thickness and Ear Formation in Cup Drawing FE Analysis 5: 51-5.

[16] Bolat, Ç., Akgün, İ.c., Göksenli, A., (2020). On The Way To Real Applications: Aluminum Matrix Syntactic Foams. European Mechanical Science. 4(3): 131-41. doi: 10.26701/ ems.703619.

[17] Yildiz, R.A., Yilmaz, S., (2020). Stress-Strain Properties of Artificially Aged 6061 Al Alloy: Experiments and Modeling. Journal of Materials Engineering and Performance. 29(9): 5764-75. doi: 10.1007/s11665-020-05080-6.

[18] Ahn, J., Chen, L., He, E., Dear, J.P., Davies, C.M., (2018). Optimisation of process parameters and weld shape of high power Yb-fibre laser welded 2024-T3 aluminium alloy. Journal of Manufacturing Processes. 34(June): 70-85. doi: 10.1016/j.jmapro.2018.05.028.

[19] Dhakal, B., Swaroop, S., (2020). Effect of laser shock peening on mechanical and microstructural aspects of 6061-T6 aluminum alloy. Journal of Materials Processing Technology. 282(February): 116640. doi: 10.1016/j.jmatprotec.2020.116640.

[20] Hoffman, C.R., (1980). Interpretıve Report On Small-Scale Test Correlations With Fracture Toughness Data. Lehigh University, (1980).

[21] Kleinberg, A., Grugan, B., Greene, K., Benzing, B., Schroeder, J., Bruce Vieth, M., et al., (1986). Fracture Mechanics Evaluation of Irradiation Embrittlement in Reactor Vessel Steels Based on the Rate Process Concept. Journal of Testing and Evaluation. 14(1): 40. doi: 10.1520/JTE10319J.

[22] Rao, B.N., Acharya, A.R., (1989). Charpy V-notch impact test: A partial alternate to ASTM E 399 fracture testing for routine quality control applications. Engineering Fracture Mechanics. 32(1):39-42. doi: 10.1016/0013-7944(89)90204$\mathrm{X}$.

[23] Sailors, R., Corten, H., (1972). Relations between material fracture toughness using fractures mechanics and transition temperature test. National Symposium on Fracture Mechanics, p. 164-91.

[24] Marandet, B., Sanz, G., n.d. Evaluation of the Toughness of Thick Medium-Strength Steels by Using Linear-Elastic Fracture Mechanics and Correlations Between. Flaw Growth and Fracture, 100 Barr Harbor Drive, PO Box C700, West Conshohocken, PA 19428-2959: ASTM International p. $72-$ 72-24.

[25] Roberts, R., Newton, C., (1984). Report on small-scale test correlations with KIC data. New York, NY: Welding Research Council.

[26] Kussmaul, K., Roos, E., (1985). Statistical evaluation of postyield fracture mechanics properties on the basis of the notched bar impact test. Nuclear Engineering and Design. 87: 123-37. doi: 10.1016/0029-5493(85)90101-3.

[27] Lucon, E., Langenberg, P., Wallln, K., Pisarski, H., (2005). The use of Charpy/fracture toughness correlations in the FITNET procedure. Proceedings of the International Conference on Offshore Mechanics and Arctic Engineering OMAE. 3(Omae): 365-8. doi: 10.1115/OMAE2005-67569.

[28] Li, X., Song, Y., Ding, Z., Bao, S., Gao, Z., (2018). A modified correlation between KJIC and Charpy V-notch impact energy of Chinese SA508-III steel at the upper shelf. 
Journal of Nuclear Materials. 505: 22-9. doi: 10.1016/j.jnucmat.2018.03.056.

[29] ASTM., (2009). Standard Test Methods for Tension Testing of Metallic Materials.

[30] ASTM International., (2018). ASTM E23 - 18, Standard Test Methods for Notched Bar Impact Testing of Metallic Materials. ASTM International.: 1-26. doi: 10.1520/E002318.

[31] ASM Handbook Committe., (1991). ASM Handbook Volume 04: Heat Treating.

[32] Xing, M. zhi., Wang, Y. gang., Jiang, Z. xiu., (2013). Dynamic Fracture Behaviors of Selected Aluminum Alloys Under Three-point Bending. Defence Technology. 9(4): 193-200. doi: 10.1016/j.dt.2013.11.002.

[33] MacMaster, F.J., Chan, K.S., Bergsma, S.C., Kassner, M.E., (2000). Aluminum alloy 6069 part II: Fracture toughness of 6061-T6 and 6069-T6. Materials Science and Engineering A. 289(1-2): 54-9. doi: 10.1016/S0921-5093(00)00918-7.

[34] Wang, Y.G., Jiang, Z.X., Wang, L.L., (2013). Dynamic tensile fracture behaviours of selected aluminum alloys under various loading conditions. Strain. 49(4): 335-47. doi: $10.1111 /$ str.12040. 